\title{
Examining Patterns of Information Exchange and Social Support in a Web-Based Health Community: Exponential Random Graph Models
}

Xuan Liu ${ }^{1 *}, \mathrm{PhD}$; Shan Jiang ${ }^{2 *}, \mathrm{PhD}$; Min Sun ${ }^{1}$, MSc; Xiaotong Chi ${ }^{1}$, MSc

${ }^{1}$ East China University of Science and Technology, Shanghai, China

${ }^{2}$ University of Massachusetts Boston, Boston, MA, United States

*these authors contributed equally

Corresponding Author:

Xuan Liu, PhD

East China University of Science and Technology

130 Meilong Rd East China University of Science and Technology

Shanghai

China

Phone: 86862164253177

Email: xuanliu@ecust.edu.cn

\section{Abstract}

Background: Although an increasing number of studies have attempted to understand how people interact with others in web-based health communities, studies focusing on understanding individuals' patterns of information exchange and social support in web-based health communities are still limited. In this paper, we discuss how patients' social interactions develop into social networks based on a network exchange framework and empirically validate the framework in web-based health care community contexts.

Objective: This study aims to explore various patterns of information exchange and social support in web-based health care communities and identify factors that affect such patterns.

Methods: Using social network analysis and text mining techniques, we empirically validated a network exchange framework on a 10-year data set collected from a popular web-based health community. A reply network was extracted from the data set, and exponential random graph models were used to discover patterns of information exchange and social support from the network.

Results: Results showed that reciprocated information exchange was common in web-based health communities. The homophily effect existed in general conversations but was weakened when exchanging knowledge. New members in web-based health communities tended to receive more support. Furthermore, polarized sentiment increases the chances of receiving replies, and optimistic users play an important role in providing social support to the entire community.

Conclusions: This study complements the literature on network exchange theories and contributes to a better understanding of social exchange patterns in the web-based health care context. Practically, this study can help web-based patients obtain information and social support more effectively.

(J Med Internet Res 2020;22(9):e18062) doi: 10.2196/18062

\section{KEYWORDS}

web-based health communities; information exchange; social support; ERGM

\section{Introduction}

\section{Background}

The rapid evolution of the internet and related technologies has created advanced virtual platforms that allow popular and pressing health topics to be discussed on the web. Unlike in the past, patients now may seek help from experts, share stories with similar patients from across the world to obtain emotional support, and keep themselves informed with latest updates about related issues [1]. The resulting environment is often referred to as web-based health communities, where users can share relevant experiences about diseases, physical conditions, and 
therapeutic schedules. Users can also consult specialists and seek opinions from experts [2]. Various web-based health communities such as PatientsLikeMe, CureTogether, DailyStrength, and Disaboom are emerging. In these platforms, patients can read stories shared by other peers, find information regarding diseases, post a new thread to initiate a conversation, and reply to others' messages to provide feedback. During these interactions, information exchange and social support occur [3]. Users can provide information by leaving messages, which generates a dynamic information exchange procedure [4]. Meanwhile, obtaining social support, especially emotional relief, from communicating with others has become one of the major purposes for patients with diseases to join web-based communities [5]. An increasing number of studies have attempted to understand how individuals interact with others in web-based health communities. For example, research has shown that patients with similar disease stages or health status are more likely to develop friendship on the web [6]. Urban users tend to provide social support to rural participants in web-based health communities [7]. A recent study has found that web-based interaction between doctors and patients does not decrease the effectiveness of information exchange compared with face-to-face communication [8]. However, studies focusing on understanding individuals' patterns of information exchange and social support in web-based health communities are still limited.

The aim of our research is to explore various patterns of information exchange and social support in web-based health care communities and identify factors that affect such patterns. On the basis of the network exchange framework [9], we discuss how patients' social interactions develop into social networks. We empirically validated the network exchange framework based on data sets collected from a leading web-based health community in China. The results from our analyses indicate that reciprocated information exchanges are likely to develop between patients, especially between web-based members who have different roles and members who are web-based friends. Some patients are more likely to receive social support, especially when they are new to the community and when they express polarized sentiment in messages. In addition, these patterns could vary depending on the topics being discussed by patients. To the best of our knowledge, this study is the first to validate the network exchange framework in the web-based health community context. This study is also the first to perform a stratified analysis of user sentiment to understand the complex information exchange and social support patterns between patients with various sentiments.

\section{Related Work}

\section{Information Exchange and Social Support}

In web-based health communities, patients can exchange information by sharing their experiences in overcoming illness, transferring medical knowledge to one another, and providing information regarding health care resources. Different communities usually specialize in different aspects. Some communities focus on specific types of disease, whereas others can provide unique services to patients. For example, in DailyStrength, patients with anxiety disorder can find a support group suggested by the community to discuss how to overcome stress or other disorders. In Tianmijiayuan, patients with diabetes and their families can post messages to share how they deal with different stages of diabetes in the long term. PatientsLikeMe provides a matching service for patients based on their profiles to quickly get in touch with other peers who have experienced or are experiencing similar diseases. Members of web-based health communities can benefit from their collective knowledge and skills by exchanging information among each other [10]. Information exchange is also a critical component in the development of many web-based communities [11]. Information exchange in web-based health communities can enhance effective communication between medical experts and patients by improving teamwork [12].

Previous studies have shown that social support plays a crucial role in helping individuals improve their health status or treat psychological problems $[13,14]$. The benefits of web-based social support come in 2 forms: informational support and emotional support [15].

By asking questions regarding health concerns on the web, users can obtain professional knowledge from experts. Moreover, patients may learn experiences from others who share similar diseases. Although such informational benefits can also come from information exchanges, obtaining social support differs from information exchange mainly in the patterns of interaction. Unlike information exchanges where the interaction is mutual, social support can be unilateral [16]. Many users provide informational support without expecting any return due to empathy [17].

Emotional support mainly comes from web-based users who share similar disease experiences or from friends of such patients. Patients can talk about what difficulties they have overcome, what they did to recover, and can encourage peers to be optimistic and fight against the disease. Some patients have reported that they received more understanding from web-based strangers than they did from offline families or friends [18]. This support could significantly enhance patients' emotional well-being [19]. As such, web-based health communities have become a platform for many patients to seek and provide emotional support [20].

Previous research has implied that social network is one of the key antecedents of social support and information exchange [15]. However, understanding information exchanges and social support in web-based health communities from a social network perspective has received limited research attention.

\section{Network Perspective of Web-Based Health Communities}

Members of web-based health communities develop a social network through communication. Such social networks provide users an opportunity to exchange information and seek social support in web-based communities $[15,21]$. By using social network analysis, attributes of nodes (ie, users) and relationships between users can be modeled and examined.

Recently, a network exchange framework has been proposed to theorize how social interactions between individuals aggregate into a social network [9]. The network exchange framework tries to explain social exchange from a network perspective by 
combining the social exchange theory and the network theory. Social interactions are viewed as processes of exchanging resources such as information, knowledge, and emotional well-being. Individual characteristics play an important role in such exchange processes. When the pair of individuals is part of a larger network, the exchange processes can be further influenced by their positional configurations, such as their social connections with others [22]. The network exchange framework has been used to explain the formation of information exchange networks in web-based communities organized around various topics, such as software [9] and automobile [23]. However, we do not find studies that apply a network exchange framework to investigate information exchange patterns in web-based health communities. This endeavor is important because web-based health communities are distinct from other more traditional web-based communities in that information being exchanged is usually sensitive, private, and requires professional medical knowledge. Handling such information gives rise to special community norms that could lead to unique social exchange patterns. As evidenced by previous studies, patterns of social interactions could vary greatly across web-based communities in different contexts $[9,24]$.

\section{Network Exchange Framework}

In this study, we develop our research hypotheses regarding information exchange in web-based health communities based on a network exchange framework for several reasons. First, we deem information and knowledge exchanged between patients as resources in web-based health communities, and thus, social exchange theory can help explain the patterns of information exchange. Second, information exchange between individuals aggregates into a network between patients because patients typically interact with multiple peers. Therefore, adopting a network perspective would better explain information exchange and social support between individual patients.

In our model, we include 3 major structural tendencies that comprise network formation in the network exchange framework: direct reciprocity, indirect reciprocity, and preferential attachment [9].

\section{Direct Reciprocity}

According to the reciprocity principle [25], individuals expect to receive information back after providing information to others. In web-based health communities, obtaining useful health care knowledge is regarded as one of the major objectives when users join a community [26]. As individuals' health care needs are usually complicated, users may ask further questions to obtain more information after receiving initial responses. Reciprocated information exchange develops in this way. Some users enjoy contributing their knowledge and receive thankful responses from others. Users are also likely to provide assistance to others who have provided them with support and then realize their intrinsic motivation $[27,28]$. Therefore, we propose the following hypothesis:

- Hypothesis 1: Reciprocated information exchange is likely to develop in web-based health communities.

The pattern of direct reciprocity could further manifest in subgroups of web-based community members. Social interaction helps people with similar characteristics to become acquainted and build trust with each other [29,30]. Homophily, the tendency for individuals to be attracted by others with similar characteristics, is an important dimension in social networks [31]. Homophily commonly occurs based on geographic and demographic characteristics such as race, religion, age, gender, residence, marital status, and interests [32,33]. In a web-based environment, similarity between users increases the frequency of their interactions [34]. A study reported that patients with similar health conditions and treatments are likely to develop friendships [6]. Another common user-related attribute in web-based health communities is user type, such as doctor, family, or patient, which users report when they join the community. As we expect homophily to exist in web-based health information exchange, we propose the following hypothesis:

- Hypothesis 2: Reciprocated information exchange is likely to develop between users who share similar concerns in web-based health communities.

Typically, web-based health community members can also become web-based friends so that they can send private messages or keep updated about each other's posts. The possibility of sending private or offline messages may decrease their visible web-based conversations. However, being capable of following friends' posts may increase their chances of reading friends' messages and initiating conversations. Furthermore, web-based friendship could develop into relational capital [35], which becomes the basis for information exchange to occur. We propose the following hypothesis for empirical tests to understand the combined effects:

- Hypothesis 3: Reciprocated information exchange is likely to develop between users who are web-based friends.

\section{Indirect Reciprocity}

Indirect reciprocity refers to returning an information exchange but not to the original provider [36]. Indirect reciprocity can be observed in web-based health communities because communicating health information usually requires specialized knowledge, but the expertise of patients is uneven. When a patient receives informational help from a knowledge provider, the patient may not be able to return the favor due to limitations in expertise. Instead, the patient may choose to provide help to others in the network as they could feel that the help is from the community as a whole, and they are willing to return the favor to the same community [37]. Previous studies have also found that new participants who received help tend to remain in the community to help others [38]. Therefore, we propose the following hypothesis:

- Hypothesis 4: Patients who receive social support tend to provide support to others who are not necessarily the support provider.

\section{Preferential Attachment}

Preferential attachment refers to a process in which a new node tends to establish connections with existing nodes that already possess many connections [39]. In the context of web-based health communities, preferential attachment translates to the 
tendency that a patient who is already involved in many web-based social interactions is likely to receive further replies. This is intuitive because highly active members contribute more and influence more people in need [40]. Such contributions are visible to the entire community, and as a rewarding mechanism, the active members may receive more help in terms of incoming social support in the future. Therefore, we propose the following hypothesis:

- Hypothesis 5: Highly active users are more likely to receive replies as social support.

Another dimension of preferential attachment in the web-based health community context is connections with new members joining the community. Contrary to traditional preferential attachment notions, we do not expect new members to be able to select which nodes to form attachments with. This is because most new patients join a community to be helped, not to help, at least in the initial periods [26]. It is the subsequent replies to the new patient that initiate social support. In web-based health care communities, such subsequent replies are likely to occur. Although the new member has not yet contributed to the community, existing members can benefit from providing support to the new member insofar as the new member becomes part of the community and adds value through social capital to the community network [35]. As such, we expect that existing community members have greater motivation to provide social support to new members.

- Hypothesis 6: In web-based health communities, new patients are more likely to receive replies as social support.

Another factor that could affect preferential attachment in web-based health communities is sentiment. Previous studies have found that users with polarized sentiment tend to receive more attention on the web. For example, expressing positive emotions helps peers improve psychological and physical health conditions [41,42]. In web-based health communities, patients may feel more comfortable getting in touch with peers who are optimistic and show positive emotions. Negative emotions attract attention in another way. In web-based health communities, many individuals are inclined to help others avoid negative feelings, such as shame, guilt, or indebtedness, especially after they receive help from others [43]. Patients expressing negative emotions are often those who have a disease or are experiencing loss, and are in need of help from peers. Therefore, social support could also go toward patients with negative moods. Overall, we expect that users who express polarized sentiment (either positive or negative) are more likely to receive attention and hence receive more replies in web-based health communities.

- Hypothesis 7: In web-based health communities, patients with polarized sentiment are more likely to receive replies as social support.

A related question is who is providing social support to the users with polarized sentiment. On the one hand, homophily plays an important role in social networking [6,32,33], and we expect that patients with overall similar sentiment valence are likely to make friends and talk to each other very often. On the other hand, the web-based health community is a platform where patients not only make friends but also help other strangers voluntarily [5]. Without being friends or knowing someone, a patient who has gone through the most difficult time could be willing to help someone who is still suffering. Meanwhile, patients in a negative mood may seek emotional support from peers who seem to be optimistic. Therefore, in addition to the homophily effect, we also expect that users with opposite sentiments are likely to leave replies to each other. The following set of hypotheses is proposed:

- Hypothesis 8a: Patients are likely to receive replies from peers with similar sentiment valence.

- Hypothesis 8b: Patients are likely to receive replies from peers with opposite sentiment valence.

\section{Methods}

\section{Data}

To test our hypotheses, we collected data from Tianmijiayuan [44], a leading web-based diabetes community in China where patients, doctors, and relatives participate in various activities. It was established in 2005 and had 247,638 members in 2018. It is one of the largest and the most active web-based nonprofit Chinese diabetes communities, targeting individuals with diabetes and helping them share information about diabetes, exchange experiences of diabetes treatment, seek emotional support, and make friends with people who are facing similar diabetic conditions. From the entire forum, we extracted users' postreply networks as well as all the textual posting content and publicly available personal information of users, such as user type and web-based friendships. Data collection was performed using a Java web crawler, with a time range from 2005 to 2015.

Tianmijiayuan has separate subforums for different discussion topics. The most popular (in terms of the number of postings) ones include Diabetes Knowledge, Communications Area for Diabetics, and Diabetic's Life. The discussions in Diabetes Knowledge are usually related to symptoms and diagnoses of different types of diabetes, patients' diet and exercise, and diabetes news. Users can make friends and participate in community activities in the Communications Area for Diabetics. In addition, they can publish their own photography, life insights, and advice for the community in the Diabetic's Life subforum. To examine whether the information exchange and social support patterns vary depending on the topic of discussion, we also performed a separate analysis on each subforum.

\section{Operationalization of Nodal Attributes}

The following nodal attributes were modeled in our study.

\section{Individual Type}

Upon registration, users choose the type of their identity as one of the following: doctors, patients' family members, patients with type $1 / 2 / X$, web service staff, or other.

\section{Activity Level}

Tianmijiayuan [44] tracks a user's number of posts, replies, web-based time, peer reviews, and numerous other factors. These factors are integrated as a numerical score to represent 
users' level of activity. Users with higher scores are considered active users. We collected this information, and users whose scores ranked among the top $25 \%$ were coded as highly active users. For robustness tests, we changed this threshold value to $20 \%, 23 \%, 27 \%$, and $30 \%$ to examine how this operationalization affects the results (seethe Robustness Tests section).

\section{Registration Time}

We classified users as long-time users or new users based on their registration time. The number of months since registration was calculated for each user, and users in the bottom $25 \%$ of registration length were coded as new users. For robustness tests, we changed this threshold value to $20 \%, 23 \%, 27 \%$, and $30 \%$ to examine how this operationalization affects the results (see the Robustness Tests section).

\section{Emotion}

Sentiment analysis was performed to determine each user's overall sentiment in the data set [45]. Specifically, a text analysis program, TextMind, was employed to assess users' sentiments on Tianmijiayuan [44]. It can identify the frequency of words associated with different emotions when users express opinions in community discussions. TextMind has been used in previous research to analyze emotional expressions in Chinese texts [46]. On the basis of the frequency of emotion-related words expressed by users in the entire forum, we found that approximately $5 \%$ of users used more negative words than positive words. These users were identified as pessimistic users with negatively polarized sentiments. An equal number of users were identified as optimistic users who used more positive words than negative words (the top 5\% users with the highest frequency of positive words were selected). The remaining users did not have extremely high proportion of positive or negative words and were identified as sentiment neutral users.

Table 1 summarizes the operationalization of the nodal attributes of the users.

Table 1. Operationalization of nodal attributes.

\begin{tabular}{|c|c|c|}
\hline Node attribute & Type & Measuring method \\
\hline User type, $\%$ & Categorical variable & $\begin{array}{ll}- & \text { 1-Users with type } 1 \text { diabetes, } 23.7 \\
\text { - } & \text { 2-Users with type } 2 \text { diabetes, } 58.3 \\
- & \text { 3-Users with type X diabetes, } 3.6 \\
\text { - } & \text { 4-Family members, } 7.0 \\
- & \text { 5-Doctors, } 0.7 \\
- & \text { 6-Web service staff, } 1.1 \\
- & \text { 7-Others, } 5.6\end{array}$ \\
\hline Activity level & Binary categorical variable & $\begin{array}{l}\text { - } 1 \text {-Highly active users } \\
\text { - } 0 \text {-Other users }\end{array}$ \\
\hline Registration time & Binary categorical variable & $\begin{array}{ll}\text { - } & 1-\text { New users } \\
\text { - } & 0 \text {-Other users }\end{array}$ \\
\hline Emotion & Categorical variable & $\begin{array}{ll}\text { - } & \text { 2-Optimistic users } \\
\text { - } & \text { 1-Pessimistic users } \\
\text { - } & 0 \text {-Neutral users }\end{array}$ \\
\hline
\end{tabular}

\section{Network Tie and Dichotomization}

In this study, the extracted postreply network was used as the base network. If a user replied to another user's thread post or reply post, a network tie was developed. The number of ties was counted as the network tie intensity.

Network dichotomization was then performed based on the threshold values of the tie intensity. According to a previous study [47], the threshold values were determined as the mean tie intensity plus one standard deviation.

\section{Exponential Random Graph Model}

Exponential random graph model (ERGM) can simultaneously model structural relationships between nodes and the effects of nodes' individual attributes on network formation [7,48,49]. The research hypotheses in our study involve various nodal attributes of web-based patients (eg, sentiment and activity level) and structural relationships between them (eg, receiving replies and reciprocating replies). With ERGM, all the complex interactions of these nodes, nodal attributes, and network ties can be incorporated simultaneously in the same model.

In ERGM, the observed network is represented as $\mathrm{Y}=\left\{\mathrm{Y}_{\mathrm{ij}}\right\}$, where $Y_{i j}$ indicates whether there is a tie between nodes $i$ and $\mathrm{j}\left(\mathrm{Y}_{\mathrm{ij}}=1\right)$ or not $\left(\mathrm{Y}_{\mathrm{ij}}=0\right)$. The ERGM generates random networks based on hypothesized network patterns (ie, configurations) and compares the generated network with the actual observed network. The more similar they are, the more likely the hypothesized network patterns exist in the actual network. The general mathematical formulation of the ERGM is as follows:

$$
\operatorname{Pr}(\mathrm{Y}=\mathrm{y})=\left(\frac{1}{\mathrm{k}}\right) \exp \left\{\sum_{\mathrm{A}} \theta_{\mathrm{A}} \mathrm{g}_{\mathrm{A}}(\mathrm{y})\right\}
$$

where the summation is over all configurations $\mathrm{A}$, y represents one kind of particular network graph y, and $\theta_{\mathrm{A}}$ is the parameter corresponding to the configuration $\mathrm{A} . \mathrm{g}_{\mathrm{A}}(\mathrm{y})$ is the network 
statistic corresponding to configuration $\mathrm{A}, \mathrm{g}_{\mathrm{A}}(\mathrm{y})=1$ if the configuration is observed in the network $\mathrm{y}$ and is 0 otherwise, and $\mathrm{k}$ is a normalizing quantity that ensures that (1) is a proper probability distribution [50]. ERGM estimates parameters $\theta_{\mathrm{A}}$ associated with each configuration, and positive and significant parameters indicate that corresponding network patterns are highly likely to occur in the network $[51,52]$.

To test our hypotheses with ERGM, we transformed our hypotheses into network patterns. Multimedia Appendix 1 shows the hypotheses and the illustration of their network patterns.

\section{Results}

\section{ERGM Results}

Table 2 summarizes the estimated parameters and $P$ values for all configurations. If a parameter is positive and significant, it indicates that the corresponding network pattern is more likely to develop than random chance [50]. During the initial tests, we found that the inclusion of a configuration for $\mathrm{H} 4$ (2-path) always resulted in model degeneracy [52]. This indicates that the pattern of indirect reciprocity hardly existed in the dichotomized postreply network. Therefore, H4 was not supported, and we excluded this network configuration from further tests.

In the subsequent section, for each hypothesis, we discuss our findings on the entire forum, and then, we compare the observations with the results in the subforums to examine how the patterns could vary depending on the topics of discussion. We deem a hypothesis to be supported only if it is supported in at least three tests.

Table 2. Results for exponential random graph model tests.

\begin{tabular}{lllllllll}
\hline Configuration & \multicolumn{2}{l}{$\begin{array}{l}\text { Entire forum (sample } \\
\text { size=1528) }\end{array}$} & \multicolumn{2}{l}{$\begin{array}{l}\text { Diabetes Knowledge (sam- } \\
\text { ple size=1188) }\end{array}$} & $\begin{array}{l}\text { Communications Area for } \\
\text { Diabetics (sample size=455) }\end{array}$ & $\begin{array}{l}\text { Diabetic's Life (sample } \\
\text { size=376) }\end{array}$ \\
& Coefficient & $P$ value & Coefficient & $P$ value & Coefficient & $P$ value & Coefficient & $P$ value \\
\hline H1: reciprocity & 3.850 & $<.001$ & 3.153 & $<.001$ & 3.509 & $<.001$ & 3.684 & $<.001$ \\
H2: type & 0.240 & $<.001$ & -0.139 & $<.001$ & 0.188 & $<.001$ & -0.287 & $<.001$ \\
H3: friend & 3.473 & $<.001$ & 3.712 & $<.001$ & 0.019 & .007 & 0.010 & .14 \\
H5: active_user & 0.012 & .76 & -0.220 & $<.001$ & -0.176 & .002 & -0.411 & $<.001$ \\
H6: new_user & 0.409 & $<.001$ & -0.110 & 0.004 & -0.400 & $<.001$ & -0.338 & .03 \\
H7: optimistic & 0.289 & $<.001$ & -1.383 & $<.001$ & -1.050 & $<.001$ & -0.819 & $<.001$ \\
H7: pessimistic & 0.144 & .045 & 0.692 & $<.001$ & -2.214 & .04 & -0.596 & .21 \\
H8a: opti-opti & -0.332 & .23 & 1.294 & 0.03 & 0.829 & .21 & -0.100 & .92 \\
H8a: pessi-pessi & -0.140 & .71 & -0.180 & 0.45 & N/A & $<.001$ & N/A & $<.001$ \\
H8b: opti-pessi & 0.168 & .51 & 0.281 & 0.17 & N/A & $<.001$ & N/A & $<.001$ \\
H8b: pessi-opti & -0.218 & .48 & 1.345 & 0.004 & N/A & $<.001$ & N/A & $<.001$ \\
\hline
\end{tabular}

${ }^{\mathrm{a}} \mathrm{N} / \mathrm{A}$ : not applicable.

\section{Hypotheses Testing Results}

First, we found positive and significant coefficients for the reciprocity configuration in the entire forum as well as 3 popular subforums, indicating that directly reciprocated information exchange was common in web-based health communities. This observation conforms to the reciprocity principle that individuals are willing to return exchanges in favor [25,53]. In web-based health communities, patients appreciate the help received from others, and gratitude is expressed in many such reciprocated messages. In addition, we also observed that a number of patient pairs reciprocated replies in different threads, especially in the Diabetes Knowledge subforum. This indicates that patients are also willing to return favors to those from whom they have received support before. In summary, H1 was supported.

A positive and significant parameter was observed for the type configuration in the entire forum, indicating that users of the same type were more likely to reciprocate messages overall.
However, the effect was negative and significant in the Diabetes Knowledge and Diabetic's Life subforums. This observation implies that conversations between users of different types were more common when the discussion topics were relevant to disease knowledge (diabetes) or personal life. For example, it is very likely that diabetes patients obtain information from doctors in the Diabetes Knowledge subforum. Moreover, when sharing personal life with web-based peers, users may be less concerned about whether others are in the same stage of diabetes as them. Note that our finding does not imply low chances of communication between any specific pair of user types in the subforums (eg, reciprocated ties specifically between two patients with type-2 diabetes in Diabetes Knowledge subforum was not tested). Instead, our finding simply implies that, overall, there was more reciprocated communication between users of different types in the 2 subforums. As a result, $\mathrm{H} 2$ was supported in the entire forum but not in the Diabetes Knowledge and Diabetic's Life subforums. 
A positive and significant parameter was observed for the friend configuration in the entire forum as well as in the Diabetes Knowledge and Communication subforums, indicating that web-based friends were very likely to exchange information frequently with each other when discussing diabetes knowledge. Being web-based friends can increase one's attention and motivation to reply to health-related posts from other community members. In addition, patients were able to obtain some timely health-related information and show empathy to others through this kind of virtual friendship [17]. This effect was not significant in Diabetic's Life subforum possibly due to the fact that when sharing personal life with web-based peers, users may be less concerned about whether others are their virtual friends. Overall, H3 was supported.

The active_user configuration was negative and significant in all subforums. Note that the activity level of a user was evaluated based on the user's log-in time and number of messages posted by the users in our data set. Therefore, our observation indicates that highly active users may stay on the web for a long time and leave many replies, but they may not necessarily receive an equally large number of replies back. This observation is different from previous findings that "popular friends get more friends" $[6,40]$ but is consistent with prior research where preferential attachment was found to be in the opposite direction in knowledge sharing communities [9]. In a community where knowledge is frequently exchanged, new members do not preferably attach to existing active members, but instead, active members play an important role in helping new members stay in the community. In the context of our postreply network in health care communities, active members frequently help others by providing social support to them (outgoing links), but they receive relatively less support from new members (incoming links) because newcomers are usually not ready to provide help yet. Overall, H5 was not supported.

We found a positive and significant parameter estimate for the new_user configuration in the entire forum, indicating that new users are likely to receive replies. One of the important goals for web-based health communities is to increase community prosperity, and hence, web forums such as Tianmijiayuan [44] encourage users to help new members. Therefore, message postings from new members could be more easily noticed in the community, making the new members more likely to receive social support from other users in the web-based health community. Interestingly, this effect was negative and significant in all 3 subforums. Note that the reply networks in the subforums only counted user interactions within each subforum. Hence, our observation implies that users who recently registered tend to participate in discussions in multiple subforums rather than staying in one specific subforum. With the rapid development of internet technology, users have changed tremendously in recent years. Our results indicate that the newly joined web-based health community participants tend to utilize resources from multiple sources. Therefore, H6 was supported only in the entire forum.

Both optimistic and pessimistic configurations were positive and significant in the entire forum, indicating that patients with polarized sentiment were more likely to receive replies in the entire forum. This confirms prior findings that polarized emotion can entail more attention [41-43]. In the 3 subforums, users with polarized sentiment were less likely to receive replies in most cases, possibly because of the same reason discussed for new users. The only exception was observed in the Diabetes Knowledge subforum, where the pessimistic configuration remained positive and significant. This implies that most of the threads seeking informational support in the knowledge sharing subcommunity could be associated with negative mood. It is intuitive because patients are likely to be anxious and desperate during the information-seeking process. Moreover, giving informational support may be prioritized for patients in desperate needs due to negativity bias [54]. Overall, H7 was supported, and negative sentiment was found to have a unique impact when seeking informational support in web-based health communities.

For communication between users of similar sentiment, neither opti-opti nor pessi-pessi was significant, indicating that users with similar sentiment were exchanging messages just as normal. This observation differs slightly from findings in previous research where homophily effects manifested in more objective attributes such as gender and health status [6]. For personal attributes such as sentiment, we found that the influence effect was stronger than the homophily effect [55]. In the Diabetes Knowledge subforum, both pessi-opti and opti-opti configurations were positive and significant, indicating that optimistic users were more likely to provide support to other users who are polarized in sentiment when exchanging health care knowledge (ie, diabetes knowledge in our data set). The effect was stronger in the pessi-opti configuration, indicating that positive attitude can influence other users, especially those who are in a negative mood. By interacting with optimistic users, pessimistic users can obtain relief, receive encouragement, and improve emotional well-being overall. To summarize, H8a and H8b were partially supported: sentiment plays a key role in communication when information exchange is involved, and social support is more likely to come from optimistic users.

\section{Robustness Tests}

Robustness tests conducted to examine whether operationalization of active users and new users could have affected our results. Our base experiment used a 25.00 (\%) threshold to identify new users and active users. In robustness tests, we used $20.00(\%), 23.00(\%), 27.00(\%)$, and $30.00(\%)$ instead to operationalize these two nodal attributes and performed ERGM analysis on the entire forum. Tables 3 and 4 show the results of the robustness tests for new users and active users. Overall, the qualitative results did not change, with the exception that the configuration for active_user became significant when the top $27.00(\%)$ or $30.00(\%)$ users were operationalized as highly active users. This was due to the fact that several users newly included in the robustness tests 3 and 4 posted very popular threads that received a large number of replies. Considering that the effect did not change when the threshold was changed to $20.00(\%)$ or $23.00(\%)$, we argue that being highly active did not have significant correlations with receiving support, and our qualitative results remain the same as in the base test. 
Table 3. Results of robustness tests, new users evaluated under different thresholds.

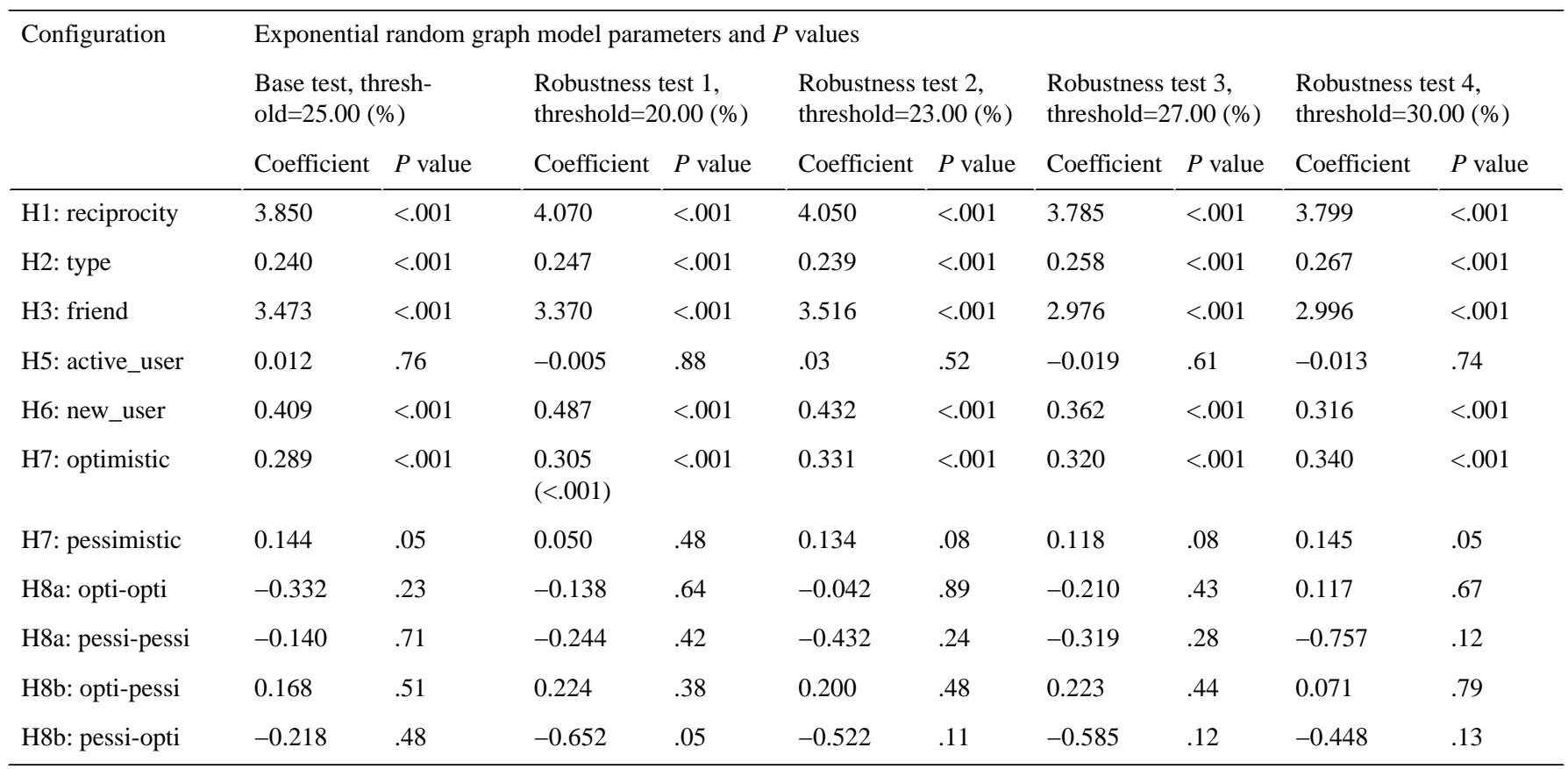

Table 4. Results of robustness tests, active users evaluated under different thresholds.

\begin{tabular}{|c|c|c|c|c|c|c|c|c|c|c|}
\hline \multirow[t]{3}{*}{ Configuration } & \multicolumn{10}{|c|}{ Exponential random graph model parameters and $P$ values } \\
\hline & \multicolumn{2}{|c|}{$\begin{array}{l}\text { Base test, thresh- } \\
\text { old }=25.00(\%)\end{array}$} & \multicolumn{2}{|c|}{$\begin{array}{l}\text { Robustness test } 1, \\
\text { threshold }=20.00(\%)\end{array}$} & \multicolumn{2}{|c|}{$\begin{array}{l}\text { Robustness test } 2, \\
\text { threshold }=23.00(\%)\end{array}$} & \multicolumn{2}{|c|}{$\begin{array}{l}\text { Robustness test } 3 \text {, } \\
\text { threshold }=27.00(\%)\end{array}$} & \multicolumn{2}{|c|}{$\begin{array}{l}\text { Robustness test } 4 \text {, } \\
\text { threshold }=30.00(\%)\end{array}$} \\
\hline & Coefficient & $P$ value & Coefficient & $P$ value & Coefficient & $P$ value & Coefficient & $P$ value & Coefficient & $P$ value \\
\hline H1: reciprocity & 3.850 & $<.001$ & 3.748 & $<.001$ & 4.052 & $<.001$ & 3.881 & $<.001$ & 3.943 & $<.001$ \\
\hline H2: type & 0.240 & $<.001$ & 0.243 & $<.001$ & 0.259 & $<.001$ & 0.260 & $<.001$ & 0.271 & $<.001$ \\
\hline $\mathrm{H} 3$ : friend & 3.473 & $<.001$ & 3.071 & $<.001$ & 3.635 & $<.001$ & 3.293 & $<.001$ & 3.130 & $<.001$ \\
\hline H5: active_user & 0.012 & .76 & -.067 & .14 & 0.040 & .31 & 0.181 & $<.001$ & 0.232 & $<.001$ \\
\hline H6: new_user & 0.409 & $<.001$ & 0.431 & $<.001$ & 0.423 & $<.001$ & 0.440 & $<.001$ & 0.497 & $<.001$ \\
\hline H7: optimistic & 0.289 & $<.001$ & 0.315 & $<.001$ & 0.310 & $<.001$ & 0.353 & $<.001$ & 0.343 & $<.001$ \\
\hline H7: pessimistic & 0.144 & .05 & 0.156 & .04 & 0.177 & .02 & 0.125 & .04 & 0.168 & .04 \\
\hline H8a: opti-opti & -0.332 & .23 & -0.069 & .82 & 0.047 & .82 & -0.229 & .36 & -0.286 & .24 \\
\hline H8a: pessi-pessi & -0.140 & .71 & -0.212 & .54 & -0.366 & .31 & -0.250 & .37 & -0.394 & .20 \\
\hline H8b: opti-pessi & 0.168 & .51 & 0.204 & .39 & 0.244 & .37 & 0.166 & .49 & 0.357 & .30 \\
\hline H8b: pessi-opti & -0.218 & .48 & -0.354 & .28 & -0.591 & .12 & -0.529 & .09 & -0.400 & .30 \\
\hline
\end{tabular}

\section{Discussion}

\section{Summary of Results}

This study uses ERGM to explore patterns of information exchange and social support in web-based health communities. Table 5 summarizes the hypotheses testing results. For hypotheses that were not supported or only partially supported, additional implications were provided. Overall, we found that reciprocity could promote information exchanges effectively. When sharing health knowledge, the homophily effect was not strong in web-based health communities, and conversations were more likely to occur between users of different types (eg, patient and doctor, web service staff, and regular users). Web-based friends were very likely to exchange information frequently with each other. Newly registered users were overall associated with better chances of receiving replies from peers. Sentiment plays an important role in web-based health communities, and users with polarized sentiment tend to receive more replies. In particular, pessimistic users were associated with better chances of informational support when knowledge is exchanged. Most of such support came from optimistic users. 
Table 5. Summary of research hypotheses and results.

\begin{tabular}{|c|c|c|}
\hline Hypothesis & Result & Implications \\
\hline $\begin{array}{l}\text { Hypothesis 1: Reciprocated information exchange is likely to de- } \\
\text { velop in web-based health communities. }\end{array}$ & Supported & In web-based communities, norm of reciprocity exists. \\
\hline $\begin{array}{l}\text { Hypothesis } 2 \text { : Reciprocated information exchange is likely to de- } \\
\text { velop between users who share similar concerns in web-based } \\
\text { health communities. }\end{array}$ & Partially supported & $\begin{array}{l}\text { In web-based communities, homophily effects are not } \\
\text { strong when health information is exchanged. }\end{array}$ \\
\hline $\begin{array}{l}\text { Hypothesis } 3 \text { : Reciprocated information exchange is likely to de- } \\
\text { velop between users who are web-based friends. }\end{array}$ & Supported & $\begin{array}{l}\text { In web-based communities, friends are likely to exchange } \\
\text { messages often. }\end{array}$ \\
\hline $\begin{array}{l}\text { Hypothesis 4: Patients who receive social support tend to provide } \\
\text { support to others who are not necessarily the support provider. }\end{array}$ & Not supported & $\begin{array}{l}\text { Indirect reciprocity hardly exists in Web-based Health } \\
\text { Community. }\end{array}$ \\
\hline $\begin{array}{l}\text { Hypothesis 5: Highly active users are more likely to receive replies } \\
\text { as social support. }\end{array}$ & Not supported & $\begin{array}{l}\text { Preferential attachment was found to be in the opposite } \\
\text { direction in knowledge sharing communities. }\end{array}$ \\
\hline $\begin{array}{l}\text { Hypothesis } 6 \text { : In web-based health communities, new users are } \\
\text { more likely to receive replies as social support. }\end{array}$ & Partially supported & $\begin{array}{l}\text { Users who recently registered tend to participate in discus- } \\
\text { sions in multiple subforums rather than staying in one } \\
\text { specific subforum. }\end{array}$ \\
\hline $\begin{array}{l}\text { Hypothesis } 7 \text { : In web-based health communities, patients with } \\
\text { polarized sentiment are more likely to receive replies on their posts. }\end{array}$ & Partially supported & $\begin{array}{l}\text { Negative sentiment was found to have a unique promoting } \\
\text { impact when seeking informational support in web-based } \\
\text { health communities. }\end{array}$ \\
\hline $\begin{array}{l}\text { Hypothesis } 8 \mathrm{a} \text { : Patients are likely to receive replies from peers } \\
\text { with similar sentiment valence. Hypothesis } 8 \text { b: Patients are likely } \\
\text { to receive replies from peers with opposite sentiment valence. }\end{array}$ & Partially supported & $\begin{array}{l}\text { Communication between sentiment polarized patients has } \\
\text { a complex pattern: only when information exchange is in- } \\
\text { volved, optimistic users are more likely to give support to } \\
\text { other sentiment polarized users. }\end{array}$ \\
\hline
\end{tabular}

\section{Contributions}

Our research makes several contributions to the literature. First, this study made the first attempt to test the network exchange framework on reply networks developed in web-based health communities. Web-based health discussions are distinct from other types of conversations in that they contain sensitive and private information and specialized knowledge. Handling such information gives rise to special community norms that could lead to unique social exchange patterns [9,24]. Our study applied ERGM under a network exchange framework and identified a number of such unique patterns. This study complements the literature on network exchange theories and contributes to a better understanding of social exchange patterns in the web-based health community context. Specifically, compared with conventional social networking sites where the formation of social ties is driven by homophily effects, we found that conversations between users of different types were more common when users discussed diabetes knowledge. It does not conflict with prior findings in the network exchange framework because information exchange is different from simply making friends. User heterogeneity could actually increase the effectiveness of knowledge sharing [7]. In terms of preferential attachment, we found that the sentiment of users interacts with discussion topics during the formation of reply networks. Generally, showing polarized sentiment resulted in better chances of receiving replies. However, when seeking knowledge regarding disease, expressing negative emotion could be a better strategy. We further found that most users who provided social support to such users were optimistic users.
Second, our research used sentiment analysis to identify optimistic users and pessimistic users from web-based health communities. To the best of our knowledge, our study is the first to examine how users with different sentiments participate differently in information exchange and social support activities.

Practically, findings from this study help patients in web-based health communities to obtain information and social support more effectively. For example, in addition to making friends, patients are encouraged to participate in discussions on health care knowledge as well as personal life to increase their visibility in the community. It is fine to express negative sentiment when seeking informational support, and showing a positive attitude could be more helpful when making friends with others.

\section{Limitations}

A limitation of this study is that our empirical analysis focused on a diabetes-related health community. Although we expect that similar patterns of information exchange and social support should be observed in other web-based health communities that provide web forums, it is interesting to see if the addition of other social features (eg, health platforms that provide feeds to users based on collaborative filtering) will affect how patients interact with each other. Moreover, the internet has changed dramatically over the 10-year time frame covered in this study. As the number of users increases over time, the resulting users in this study after network dichotomization might represent a more recent sample. Performing a temporal analysis to examine how social support patterns evolve dynamically could also be a future direction. 


\section{Acknowledgments}

This research was supported by the National Natural Science Foundation of China with grants $(71971082,71471064,71371005$, and 91646205), the Key Soft Science Projects in Shanghai (grant number 19692106700), the Humanity and Social Science Youth Foundation of the Ministry of Education of China (grant number 18YJC630068), and Fundamental Research Funds for the Central Universities.

\section{Conflicts of Interest}

None declared.

\section{Multimedia Appendix 1}

Research hypotheses, levels of analysis, and graphical illustrations.

[PNG File, 143 KB-Multimedia Appendix 1]

\section{References}

1. Wang X, Parameswaran S, Bagul DM, Kishore R. Can online social support be detrimental in stigmatized chronic diseases? A quadratic model of the effects of informational and emotional support on self-care behavior of HIV patients. J Am Med Inform Assoc 2018 Aug 1;25(8):931-944. [doi: 10.1093/jamia/ocy012] [Medline: 29684190]

2. Comerford M, Fogel R, Bailey JR, Chilukuri P, Chalasani N, Lammert CS. Leveraging social networking sites for an autoimmune hepatitis genetic repository: pilot study to evaluate feasibility. J Med Internet Res 2018 Jan 18;20(1):e14 [FREE Full text] [doi: 10.2196/jmir.7683] [Medline: 29348111]

3. Zhang S, O'Carroll BE, Owen J, Bakken S, Elhadad N. Online cancer communities as informatics intervention for social support: conceptualization, characterization, and impact. J Am Med Inform Assoc 2017 Mar 1;24(2):451-459 [FREE Full text] [doi: 10.1093/jamia/ocw093] [Medline: 27402140]

4. Sudau F, Friede T, Grabowski J, Koschack J, Makedonski P, Himmel W. Sources of information and behavioral patterns in online health forums: observational study. J Med Internet Res 2014 Jan 14;16(1):e10 [FREE Full text] [doi: 10.2196/jmir.2875] [Medline: 24425598]

5. Liu X, Sun M, Li J. Research on gender differences in online health communities. Int J Med Inform 2018 Mar;111:172-181. [doi: 10.1016/j.ijmedinf.2017.12.019] [Medline: 29425630]

6. Song X, Jiang S, Yan X. Collaborative Friendship Networks in Online Healthcare Communities: An Exponential Random Graph Model Analysis. Smart Healthpringer International Publishing 2014:-. [doi: 10.1007/978-3-319-08416-9 8]

7. Goh JM, Gao G, Agarwal R. The creation of social value: can an online health community reduce rural-urban health disparities? MIS Q 2016 Jan 1;40(1):247-263. [doi: 10.25300/MISQ/2016/40.1.11]

8. Tates K, Antheunis ML, Kanters S, Nieboer TE, Gerritse MB. The effect of screen-to-screen versus face-to-face consultation on doctor-patient communication: an experimental study with simulated patients. J Med Internet Res 2017 Dec 20;19(12):e421 [FREE Full text] [doi: 10.2196/jmir.8033] [Medline: 29263017]

9. Faraj S, Johnson SL. Network exchange patterns in online communities. Organ Sci 2011 Dec;22(6):1464-1480. [doi: 10.1287/orsc. 1100.0600$]$

10. Poortvliet PM. Examining the effects of mastery and performance goals on information exchange processes. Netherland $\mathrm{J}$ Psychol 2009 Jun;65(2):53-61. [doi: 10.1007/bf03080127]

11. Jin J, Li Y, Zhong X, Zhai L. Why users contribute knowledge to online communities: an empirical study of an online social Q\&A community. Inf Manag 2015 Nov;52(7):840-849. [doi: 10.1016/j.im.2015.07.005]

12. Aubé C, Brunelle E, Rousseau V. Flow experience and team performance: the role of team goal commitment and information exchange. Motiv Emot 2013 May 30;38(1):120-130. [doi: 10.1007/s11031-013-9365-2]

13. Johnsen MC. Social Support Measurement and Intervention: A Guide for Health and Social Scientists. PS 2001 Oct;52(10):1404-1404. [doi: 10.1176/appi.ps.52.10.1404]

14. Uchino BN. Social support and health: a review of physiological processes potentially underlying links to disease outcomes. J Behav Med 2006 Aug;29(4):377-387. [doi: 10.1007/s10865-006-9056-5] [Medline: 16758315]

15. Langford CP, Bowsher J, Maloney JP, Lillis PP. Social support: a conceptual analysis. J Adv Nurs 1997 Jan;25(1):95-100. [doi: 10.1046/j.1365-2648.1997.1997025095.x] [Medline: 9004016]

16. Uehara E. Dual exchange theory, social networks, and informal social support. Am J Sociology 1990 Nov;96(3):521-557. [doi: $10.1086 / 229571]$

17. Nambisan P. Information seeking and social support in online health communities: impact on patients' perceived empathy. J Am Med Inform Assoc 2011 May 1;18(3):298-304 [FREE Full text] [doi: 10.1136/amiajnl-2010-000058] [Medline: 21486888]

18. Rheingold H. The Virtual Community: Homesteading on the Electric Frontier. New York, USA: HarperPerennial; 1993. 
19. Cacciamani G, Aron M, Gill I, Desai M. Oncological outcome according to attainment of pentafecta after robot assisted radical cystectomy among bladder cancer patients using KORARC database (730 multicenter robot radical cystectomy database). BJU Int 2020 Jul 18:-. [doi: 10.1111/bju.15222] [Medline: $\underline{32870582}$ ]

20. Wang X, Zhao K, Street N. Analyzing and predicting user participations in online health communities: a social support perspective. J Med Internet Res 2017 Apr 24;19(4):e130 [FREE Full text] [doi: 10.2196/jmir.6834] [Medline: 28438725]

21. Wellman B. For a Social Network Analysis of Computer Networks:a Sociological Perspective on Collaborative Work and Virtual Community. In: Proceedings of the 1996 ACM SIGCPR/SIGMIS conference on Computer personnel research. 1996 Presented at: SIGCPR'96; April 11-13, 1996; New York, USA. [doi: 10.1145/238857.238860]

22. Walker HA, Thye SR, Simpson B, Lovaglia MJ, Willer D, Markovsky B. Network exchange theory: recent developments and new directions. Soc Psychol Q 2000 Dec;63(4):324. [doi: 10.2307/2695843]

23. Lee JY, Yang C, Hsu C, Wang J. A longitudinal study of leader influence in sustaining an online community. Ing Manag 2019 Mar;56(2):306-316. [doi: 10.1016/j.im.2018.10.008]

24. Yuqing R, Kraut R, Kiesler S. Applying common identity and bond theory to design of online communities. Organ Stud 2016 Jun 30;28(3):377-408. [doi: 10.1177/0170840607076007]

25. Gouldner AW. The norm of reciprocity: a preliminary statement. Am Sociol Rev 1960 Apr;25(2):161. [doi: 10.2307/2092623]

26. Dahlke DV, Fair K, Hong YA, Beaudoin CE, Pulczinski J, Ory MG. Apps seeking theories: results of a study on the use of health behavior change theories in cancer survivorship mobile apps. JMIR Mhealth Uhealth 2015 Mar 27;3(1):e31 [FREE Full text] [doi: 10.2196/mhealth.3861] [Medline: 25830810]

27. Wasko ML, Faraj S. Why should I share? Examining social capital and knowledge contribution in electronic networks of practice. MIS Q 2005;29(1):35. [doi: 10.2307/25148667]

28. Wu B, Jiang S, Chen H. Effects of individuals' motivations on communications in online health forums. Soc Behav Personal 2016 Mar 23;44(2):299-312. [doi: 10.2224/sbp.2016.44.2.299]

29. Chang MK, Cheung W, Tang M. Building trust online: interactions among trust building mechanisms. Inf Manag 2013 Nov;50(7):439-445. [doi: 10.1016/j.im.2013.06.003]

30. Raghavun K, Vassileva J. Visualizing Reciprocity to Motivate Participation in an Online Community. In: 5th IEEE International Conference on Digital Ecosystems and Technologies. 2011 Presented at: IEEE DEST'11; May 31-June 3, 2011; Daejeon, South Korea. [doi: 10.1109/DEST.2011.5936604]

31. Granitz NA, Koernig SK, Harich KR. Now it's personal. J Mark Educ 2008 Oct 13;31(1):52-65. [doi: $10.1177 / 0273475308326408]$

32. Aiello LM, Barrat A, Schifanella R, Cattuto C, Markines B, Menczer F. Friendship prediction and homophily in social media. ACM Trans Web 2012 May 1;6(2):1-33. [doi: 10.1145/2180861.2180866]

33. Thelwall M. Homophily in MySpace. J Am Soc Inf Sci 2009 Feb;60(2):219-231. [doi: 10.1002/asi.20978]

34. Hogg MA, Terry DI. Social identity and self-categorization processes in organizational contexts. Acad Manage Rev 2000 Jan;25(1):121-140. [doi: 10.5465/amr.2000.2791606]

35. Nahapiet J, Ghoshal S. Social capital, intellectual capital, and the organizational advantage. AMR 1998 Apr;23(2):242-266. [doi: $10.5465 / \mathrm{amr} .1998 .533225]$

36. Takahashi N. The emergence of generalized exchange. Am J Sociol 2000 Jan;105(4):1105-1134. [doi: 10.1086/210400]

37. Katz JE, Rice RE. Social consequences of Internet use: Access, involvement and interaction. Cambridge, MA: MIT Press 2002:-. [doi: 10.7551/mitpress/6292.001.0001]

38. Joyce E, Kraut RE. Predicting continued participation in newsgroups. J Comp Mediated Comm 2006 Apr;11(3):723-747. [doi: 10.1111/j.1083-6101.2006.00033.x]

39. Watts DJ. The 'new' science of networks. Annu Rev Sociol 2004 Aug;30(1):243-270. [doi: 10.1146/annurev.soc.30.020404.104342]

40. Zhao K, Yen J, Greer G, Qiu B, Mitra P, Portier K. Finding influential users of online health communities: a new metric based on sentiment influence. J Am Med Inform Assoc 2014 Oct;21(e2):e212-e218 [FREE Full text] [doi: 10.1136/amiajnl-2013-002282] [Medline: 24449805]

41. Fredrickson BL. The broaden-and-build theory of positive emotions. Philos Trans R Soc Lond B Biol Sci 2004 Sep 29;359(1449):1367-1378 [FREE Full text] [doi: 10.1098/rstb.2004.1512] [Medline: 15347528]

42. Yoo W, Namkoong K, Choi M, Shah DV, Tsang S, Hong Y, et al. Giving and receiving emotional support online: communication competence as a moderator of psychosocial benefits for women with breast cancer. Comput Human Behav 2014 Jan;30:13-22 [FREE Full text] [doi: 10.1016/j.chb.2013.07.024] [Medline: 24058261]

43. Yang F, Zhong B, Kumar A, Chow S, Ouyang A. Exchanging social support online: a longitudinal social network analysis of irritable bowel syndrome patients' interactions on a health forum. Journalism Mass Commun Q 2017 Sep 28;95(4):1033-1057. [doi: 10.1177/1077699017729815]

44. Tianmijiayuan. URL: http://bbs.tnbz.com/ [accessed 2020-09-11]

45. Feldman R. Techniques and applications for sentiment analysis. Commun ACM 2013 Apr;56(4):82-89. [doi: $\underline{10.1145 / 2436256.2436274]}$ 
46. Gao R, Hao B, Li H, Gao Y, Zhu T. Developing Simplified Chinese Psychological Linguistic Analysis Dictionary for Microblog. In: International Conference on Brain and Health Informatics. 2013 Presented at: BHI'13; October 29-31, 2013; Maebashi, Japan. [doi: 10.1007/978-3-319-02753-1 36]

47. Jiang S, Gao Q, Chen H, Roco MC. The roles of sharing, transfer, and public funding in nanotechnology knowledge-diffusion networks. J Assn Inf Sci Tec 2014 Jun 10;66(5):1017-1029. [doi: 10.1002/asi.23223]

48. Heaney MT. Multiplex networks and interest group influence reputation: an exponential random graph model. Soc Netw 2014 Jan;36:66-81. [doi: 10.1016/j.socnet.2012.11.003]

49. Yan L, Peng J, Tan Y. Network dynamics: how can we find patients like us? Ing Syst Res 2015 Sep;26(3):496-512. [doi: 10.1287/isre.2015.0585]

50. Robins G, Pattison P, Kalish Y, Lusher D. An introduction to exponential random graph ( $\mathrm{p}^{*}$ ) models for social networks. Soc Netw 2007 May;29(2):173-191. [doi: 10.1016/j.socnet.2006.08.002]

51. Kolaczyk ED, Csárdi G. Statistical Analysis of Network Data With R. New York, USA: Springer; 2014.

52. Snijders TA, Pattison PE, Robins GL, Handcock MS. New specifications for exponential random graph models. Sociol Method 2016 Jun 23;36(1):99-153. [doi: 10.1111/j.1467-9531.2006.00176.x]

53. Barak A, Gluck-Ofri O. Degree and reciprocity of self-disclosure in online forums. Cyberpsychol Behav 2007 Jun;10(3):407-417. [doi: 10.1089/cpb.2006.9938] [Medline: 17594265]

54. Rozin P, Royzman EB. Negativity bias, negativity dominance, and contagion. Pers Soc Psychol Rev 2016 Dec 21;5(4):296-320. [doi: 10.1207/S15327957PSPR0504 2]

55. Aral S, Muchnik L, Sundararajan A. Distinguishing influence-based contagion from homophily-driven diffusion in dynamic networks. Proc Natl Acad Sci U S A 2009 Dec 22;106(51):21544-21549 [FREE Full text] [doi: 10.1073/pnas.0908800106] [Medline: 20007780]

\section{Abbreviations}

ERGM: exponential random graph model

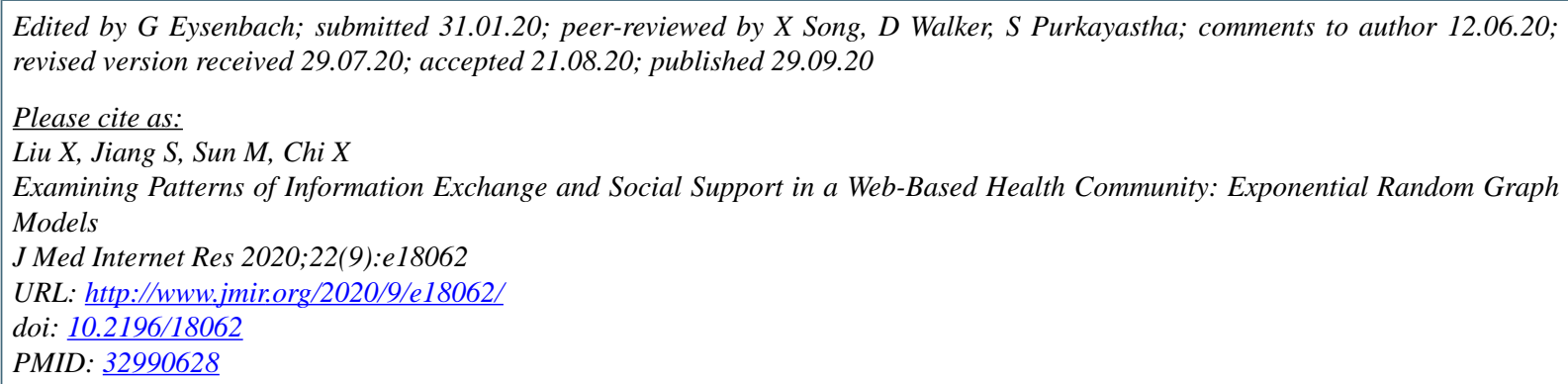

(CXuan Liu, Shan Jiang, Min Sun, Xiaotong Chi. Originally published in the Journal of Medical Internet Research (http://www.jmir.org), 29.09.2020. This is an open-access article distributed under the terms of the Creative Commons Attribution License (https://creativecommons.org/licenses/by/4.0/), which permits unrestricted use, distribution, and reproduction in any medium, provided the original work, first published in the Journal of Medical Internet Research, is properly cited. The complete bibliographic information, a link to the original publication on http://www.jmir.org/, as well as this copyright and license information must be included. 